\title{
Prevalence and intensity of urinary schistosomiasis among school age children in Ikota, Southwestern Nigeria
}

\section{Oluwaseun Bunmi Awosolu ${ }^{1, *}$, Olufemi Joseph Akinnifesi ${ }^{1}$, Adekola Saheed Salawu ${ }^{2}$, Yemisi Florence Omotayo ${ }^{1}$, Ebenezer Tolulope Obimakinde ${ }^{1}$ and Christian Olise ${ }^{1}$}

\author{
${ }^{1}$ Parasitology and Public Health Unit. Department of Biology. Federal University of \\ Technology. Akure. Nigeria.*Email: awosconik@yahoo.co.uk. \\ ${ }^{2}$ Department of Zoology. Obafemi Awolowo University. Ile Ife Osun State. Nigeria.
}

\begin{abstract}
Schistosomiasis is a water-borne parasitic disease second to malaria in terms of socio-economic importance. Epidemiological data upon which management control could be based is lacking in Ikota, Ondo State, Nigeria. The present study evaluated the prevalence and intensity of urinary schistosomiasis among School age children in Ikota, Ifedore Local Government Area (LGA) of Ondo State, Nigeria. Urine samples were first examined macroscopically for haematuria while reagent strip was used to detect proteinuria after which sedimentation method was used to analyse the samples for characteristic features of the Schistosoma haematobium. Data obtained from the study were analyzed using Pearson's Chi-Square Test. A total of 150 subjects were examined, out of which 76 (50.7\%) were male and 74 (49.3\%) were female. Results obtained from this study revealed a total prevalence of $24 \%$ with mean intensity of $21.82 \mathrm{egg} / 10 \mathrm{~mL}$ of urine. The percentage distribution of the infection among the sexes showed that the male students had a lower prevalence of $21.1 \%$ of infection than their female counterparts who had $27.0 \%$ prevalence with no significant difference $(\mathrm{P}>0.05)$. It was also observed that age group 5-9 had the highest prevalence and mean intensity of $100 \%$ and $13.50 \mathrm{egg} / 10 \mathrm{~mL}$ of infection with no significant difference $(\mathrm{P}>0.05)$. In the same vein, sources of water vary significantly among the subjects $(\mathrm{p}<0.05)$. Those who depended on river water $(75.0 \%)$ had the highest level of infection. Therefore, it is evident that $S$. haematobium infection is prevalent among the study subjects and appropriate management control strategies should be deployed to the study area.
\end{abstract}

Keywords: Schistosoma haematobium; Prevalence; Intensity; Urinary schistosomiasis; Ikota.
Received

April 06, 2019

Accepted

July 23, 2019

Released

August 31, 2019

Full Text Article

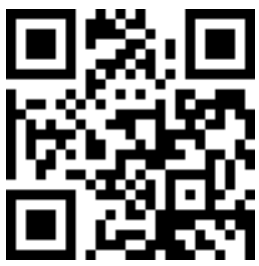

ORCID

(ㄱ) 0000-0002-5213-7397

Oluwaseun Bunmi Awosolu

(1) 0000-0002-5888-2347 Olufemi Joseph Akinnifesi

D 0000-0003-1143-0789

Adekola Saheed

Salawu

(D) 0000-0002-5032-907X

Yemisi Florence

Omotayo

(D) 0000-0002-0482-8724

Ebenezer Tolulope Obimakinde

D 0000-0001-6179-2556

Christian Olise 


\section{Introduction}

Urinary schistosomiasis, a
disease condition resulting from
infection by a digenetic trematode,
S. haematobium is one of the most
prevalent neglected tropical diseases
(NTDs) and a public health problem in
third world countries of Asia and Africa.
The disease has been found to be
endemic in sub-Saharan African
countries with approximately 779
million estimated to be at risk (Adewunmi et al., 1991; Dawaki et al., 2015; Anorue et al., 2017). Nigeria is one of the African countries with the most incidence of schitosomasis, prevalence ranging between 2\%-90\% (Ugbomoiko, 2000; Awosolu, 2016; Bishop and Akoh, 2018). Prevalence and intensity are found to be highest among adolescents, young adults and most especially schoolage children in endemic areas (Hotez, 2009). The parasite niched in the venous plexus of humans, draining the urinary bladder (WHO, 2002).

Haematuria (blood in urine) results from the irritation of the granulomatous caused by terminal spined deposited by the parasite in the venous plexus, causing ulceration and pseudo-polyposis of the vesical and ureteral wall. This is a predominant symptom of infection; others include dysuria, proteinuria etc. People contract infection by indulging in various open water activities in cercaria infested water bodies (Ivoke et al., 2014). Various species of the planorbid snail Bulinus have been incriminated as the intermediate host of $S$. haematobium in both rural and urban communities.

In Nigeria, efforts have been intensified in determining the prevalence of Urinary schistosomiasis among both rural and urban dwellers, however there is a dearth of epidemiological data on the prevalence and intensities of S. haematobium infection in Ikota, Ifedore LGA of Ondo State, Nigeria.
Hence this study intends to elucidate the relationship between demographic factors of the population used in this study and the prevalence and intensity of urinary schistosomiasis.

\section{Materials and method}

\section{Study area}

The research was carried out in Ikota, a town in Ifedore LGA of Ondo State, Nigeria. Ikota is about $14 \mathrm{~km}$ away from Akure, the capital of Ondo State, located between longitude $70^{\circ} 10^{\prime} \mathrm{N}$ and $50^{\circ} 05^{\prime} \mathrm{E}$ and latitude $7.1670^{\circ} \mathrm{N}$ and $5.0830^{\circ}$ E. Ikota has an ambient average temperature of about $27{ }^{\circ} \mathrm{C}$, an average annual rainfall of about $2,378 \mathrm{~mm}$ and relative humidity of $80 \%$. The area has two distinct seasons, the wet season; that ranges from March to October and the dry season; ranging from November to February. The wet season is characterized by heavy rains with overflowing river banks and streams while the dry season is characterized by hot, dry winds. The major occupation of the inhabitants are farming, fishing and trading. Rivers and streams in this region are used by farmers, traders and children for irrigation, domestic and recreational purposes, respectively.

\section{Ethical consideration}

Prior to the commencement of the research, approval was sought from the Health Research Ethics Committee (HREC) of the University, the Principal of the school where the study was conducted and from students for collection of urine samples. All were clearly informed about the aims and objectives of the research. samples

Study subject and collection of

The students of United Comprehensive Secondary School, Ikota, Nigeria, were the subject of the research. Students from Junior Secondary 1 to 
Senior Secondary 3 were screened for the infection. The field survey was done during the wet season between June and July 2015. The survey was carried out using urine sample collection and questionnaires administration. Urine samples were collected between 10:00 h am and 2:00 $\mathrm{h}$ pm daily because the body metabolism at this time is high and also after two weeks of treating the students with prazequantel.

Each student was given a clean, sterilised dry screw capped $25 \mathrm{~mL}$ sample bottle with identification number and was instructed on mode of sample collection. The identification number on the sample bottle was written on the questionnaire given to each student. During the collection process, test strip was dipped in each urine sample to check for proteinuria and haematuria, after which the result was recorded. Two drops of $10 \%$ formalin was added to each urine sample to preserve it. The urine samples were transported to the research laboratory of Department of Biology, Federal University of Technology, Akure.

\section{samples \\ Laboratory analysis of urine}

Sedimentation method was used for the analysis. The urine samples were first examined macroscopically for haematuria after which $10 \mathrm{~mL}$ of each urine sample was placed in a centrifuge tube and centrifuged at $4000 \mathrm{rpm}$ for 5 mi. Following centrifugation, the supernatant was decanted while the sediment was examined under the microscope using $10 \mathrm{x}$ objective lens. Each field of the slide was examined and the intensity was recorded as mean egg count/10 mL of urine.

\section{Statistical analysis}

Data obtained from this study were analyzed using SPSS Version 20. Pearson's Chi-Square Test was used to test for significance between the prevalence of subject age and gender. Differences in mean egg count between dichotomous variables and variables with more than two levels were explored using student's T-tests and one-way analysis of variance, respectively.

\section{Results}

A total of 150 urine samples were collected, coupled with 150 questionnaires out of which 76 (50.7\%) were male and 74 (49.3\%) were female. Result obtained from this research revealed a total of 36 of the students infected, given a total prevalence of $24 \%$ with mean intensity of $21.82 \mathrm{egg} / 10 \mathrm{~mL}$ of urine (Table 1).

Table 1 shows the prevalence and intensity of $S$. haematobium among the different age groups. Microscopic analysis revealed that students within the age group of 5-9 with 100\% prevalence and $13.5 \mathrm{egg} / 10 \mathrm{~mL}$ mean intensity of infection had the highest prevalence and mean intensity of infection followed by age group 15-19 with prevalence and mean intensity of $23.8 \%$ and $4.5 \mathrm{egg} / 10 \mathrm{~mL}$ of urine respectively while students within the age range of 10-14 with prevalence and mean intensity of infection of $23.1 \%$ and $3.82 \mathrm{egg} / 10 \mathrm{~mL}$ of urine respectively presented the lowest prevalence and mean intensity of infection. It was observed that the prevalence and mean intensity of infection decrease relatively with increase in age except for age group 
10-14. However, statistical analysis revealed that there was no significant difference in both prevalence and mean intensity of infection in relation to the different age groups $(\mathrm{P}>0.05)$.

Table 1. Prevalence and intensity of urinary schistosomiasis among students of Comprehensive High School, Ikota, with respect to age groups.

\begin{tabular}{lccc}
\hline Age group & Examined & Positive/Prevalence (\%) & $\begin{array}{c}\text { Mean (S.D.) intensity of } \\
\text { infection (egg/10 mL of urine) }\end{array}$ \\
\hline $5-9$ & 2 & $2(100)$ & $13.50(0.7)$ \\
$10-14$ & 65 & $15(23.1)$ & $3.82(7.4)$ \\
$15-19$ & 80 & $19(23.8)$ & $4.50(9.3)$ \\
$>20$ & 3 & $0(0)$ & $0(0)$ \\
\hline Total & 150 & $36(24.0)$ & 21.82 \\
\hline & & $\mathrm{P}=0.06$ & $\mathrm{P}=0.33$ \\
\hline
\end{tabular}

Microscopic analysis revealed that, of the 76 male students that were examined during the study, $16(21.1 \%)$ were positive for $S$. haematobium while $20(27.0 \%)$ of the 74 female students that were examined were positive for the infection. Statistical analysis showed no significant difference in prevalence of infection in respect to the sexes $(\mathrm{P}>0.05)$ (Table 2).

Table 2. Prevalence of urinary schistosomiasis among students of Comprehensive High School, Ikota, in relation to sexes.

\begin{tabular}{lcc}
\hline Sex & Examined & Positive/ Prevalence (\%) \\
\hline Male & 76 & $16(21.1)$ \\
Female & 74 & $20(27.0)$ \\
Total & 150 & $36(24.0)$ \\
\hline & & $P=0.40$ \\
\hline
\end{tabular}

Table 3 shows the prevalence of infection among the students with respect to their fathers' occupation. Result shows that 16 (28.6\%) of students whose fathers are farmer were positive for S. haematobium, 10 (22.2\%) of the students whose fathers are trader were positive of the infection, 5 (15.6\%) of students whose fathers are civil servant were positive while $5(31.3 \%)$ of the students whose fathers are artisan were positive for the infection. Students whose fathers are artisan recorded the highest prevalence while those whose fathers engage in fishing recorded the lowest prevalence of $0 \%$ with no significance ( $\mathrm{P}>0.05)$. 
Table 3. Prevalence of urinary schistosomiasis among students of Comprehensive High School, Ikota, in relation to father's occupation.

\begin{tabular}{lcc}
\hline Father's occupation & Examined & Positive/Prevalence (\%) \\
\hline Farming & 56 & $16(28.6)$ \\
Treading & 45 & $10(22.2)$ \\
Artisan & 16 & $5(31.3)$ \\
Fishing & 1 & $0(0)$ \\
Civil Servant & 32 & $5(15.6)$ \\
\hline Total & 150 & $36(24.0)$ \\
\hline & & $\mathrm{P}=0.613$ \\
\hline
\end{tabular}

Furthermore, result shows that 4 (33.3\%) of students whose mothers are farmer were positive for S. haematobium, $27(23.3 \%)$ of the students whose mothers are trader were positive for $S$. haematobium. It was also recorded that $3(15.4 \%)$ of students whose mothers are civil servant were positive for the infection while $2(33.3 \%)$ of the students whose mothers are artisan were positive. Students whose parents are traders are shown to have the highest prevalence with no significance $(P>0.05)$ (Table 4$)$.

Table 4. Prevalence of urinary schistosomiasis among students of Comprehensive High School, Ikota, with respect to mother's occupation.

\begin{tabular}{lcc}
\hline Mother's occupation & Examined & Positive/Prevalence (\%) \\
\hline Farming & 12 & $4(33.3)$ \\
Trading & 116 & $27(23.3)$ \\
Artisan & 9 & $3(33.3)$ \\
Civil Servant & 13 & $2(15.4)$ \\
\hline Total & 150 & $36(24.0)$ \\
\hline
\end{tabular}

Prevalence of S. haematobium among students with respect to their fathers' educational level is presented in Table 5. Result shows that $3(17.6 \%)$ of the students whose fathers stopped at primary education were positive for the infection. $21(25.3 \%)$ of the students whose father stopped at secondary education were positive for the infection while $12(24.0 \%)$ of the students whose father had tertiary education were found to be positive. Students whose fathers stopped at the secondary level of education recorded the highest prevalence. Statistical analysis revealed no significance in the rate of infection in this group $(\mathrm{P}>0.05)$. 
Table 5. Prevalence of urinary schistosomiasis among students of Comprehensive High School, Ikota, in relation to father's education

\begin{tabular}{lcc}
\hline Father's educational level & Examined & Positive/Prevalence (\%) \\
\hline Primary & 17 & $3(17.6)$ \\
Secondary & 83 & $21(25.3)$ \\
Tertiary & 50 & $12(24.0)$ \\
\hline Total & 150 & $36(24.0)$ \\
\hline & & $\mathrm{P}=0.801$ \\
\hline
\end{tabular}

Table 6 shows the prevalence of $S$. haematobium among students in respect to their mothers' occupation. Of all the students examined 9 (32.1\%) of the students whose mother stopped at primary education were positive for the infection. $16(19.8 \%)$ of the students whose mother stopped at secondary education were positive for the infection while $11(26.8 \%)$ of the students whose mothers had tertiary education were found to be positive for $S$. haematobium. Students whose mothers had primary education had the highest prevalence of infection. There was no significant difference in the rate of infection among this group $(\mathrm{P}>0.05)$.

Table 6. Prevalence of urinary schistosomiasis among students of Comprehensive High School, Ikota according to mother's education.

\begin{tabular}{lcc}
\hline Mother's educational level & Examined & Positive/Prevalence (\%) \\
\hline Primary & 28 & $9(32.1)$ \\
Secondary & 81 & $16(19.8)$ \\
Tertiary & 41 & $11(26.8)$ \\
\hline Total & 150 & $36(24.0)$ \\
\hline & & $\mathrm{P}=0.373$ \\
\hline
\end{tabular}

In respect to the different water sources used by the students, the prevalence of infection is presented in Table 7. It was observed that $18(22.5 \%)$ of the students who depend on tap water as major source of water were positive for $S$. haematobium. Among those students who depend mainly on well water, $12(19.4 \%)$ of them were infected while those who depend on river as water source presented the prevalence of $6(75.0 \%)$. It was observed that those who depend on river water presented the highest prevalence of infection while those of well water had the lowest prevalence. Statistical analysis revealed that there was a significant difference in the prevalence of infection among this group $(\mathrm{P}<0.05)$. 
Table 7. Prevalence of urinary schistosomiasis among students of Comprehensive High School, Ikota with respect to sources of water.

\begin{tabular}{lcc}
\hline Sources of water & Examined & Positive/Prevalence (\%) \\
\hline Tap & 80 & $18(22.5)$ \\
Well & 62 & $12(19.4)$ \\
River & 8 & $6(75.0)$ \\
\hline Total & 150 & $36(24.0)$ \\
\hline & & $P=0.004$ \\
\hline
\end{tabular}

\section{Discussion}

The prevalence $\begin{array}{r}\text { of } \\ \text { infection among }\end{array}$
S. haematobium school students of
secondary Homprehensive High School in Ikota,
Ifedore, LGA of Ondo State, Nigeria, was
evaluated in this study. The result of this
research revealed low prevalence of $24 \%$
among the individuals examined. This is
lower compared to other studies within
and outside Ondo State, Nigeria (Akogun
and Obadiah, 1996; Duna and Bristone,
2000; Umar and Parakoyi, 2005; Oniya
and Jeje, 2010; Ugbomoiko et al., 2010;
Awosolu, 2016). However, it is higher
than the 2.07\% and 16.3\% reported in
Jos (Dawet et al., 2012) and Nasarawa
(Reuben et al., 2013) in North Central of
Nigeria, respectively. The prevalence of
infection in this study area is due to
many factors including socio-economic
factors and environmental factors which
result into water-contact activities
(Ugbomoiko, 2010; Awosolu, 2016). This
is also in line with the report of
Nkengazong et al. (2013), who showed
that villages that lack access to pipe-
borne water maintained high level of
infection.

Furthermore, there is decrease in infection as the age increase. The highest prevalence of infection among age group was recorded among the age group 5-9. However, there is no significant difference $(p>0.05)$. This is an indication that all age group are exposed to $S$. haematobium equally. This is similar to a study conducted in Abeokuta (Ekpo et al., 2010). This might be due to the level of immunity, frequent water contact activities around water bodies and the level to which the water is infested with the intermediate host Bulinus sp.

Furthermore, sex specific pattern of infection revealed a higher prevalence of S. haematobium infection among females $(27.0 \%)$ compared to males (21.1\%) though there is no significant difference. This report ran contrary to the works reported in Gusau (Bala et al., 2012) and Benue State (Houmsou et al., 2012) which had highest prevalence in males. On the other hand, it is in line with the report of Ekpo et al. (2010). The higher outcome in females might be associated with females being more engaged in domestic functions involving frequent river visit compared to their male counterparts.

Following other sociodemographic evaluations, prevalence according to parent's occupation showed students whose fathers are artisans had the highest $(31.3 \%)$. However, it is not statistically significant $(p>0.05)$ and this means that the father' occupation does not necessarily have effect on contracting the infection. This conformed to the research reported by Houmsou et al. (2012) in Benue State.

Additionally, the education level of respondent's parent did not have significant influence on prevalence among both sexes. With regards to water source, those who depend on river water have higher prevalence of infection compared to other sources. This report is in line with the work of Bigwan et al. (2012) who reported high prevalence 
with population dependent on rivers water. This higher prevalence may be due to reasons that river water is the major source found in the study area. Overall, the mean intensity of infection peaked at $21.82 \mathrm{egg} / 10 \mathrm{~mL}$ of urine. The intensity was found to increase across the ages except for $>20$ who showed no intensity due to small sample size.

\section{Conclusion}

While it is evident that results from this study area showed low prevalence and intensity levels, efforts to control schistosomiasis to a more tolerable level should be intensified. Further intervention programmes is recommended for Ikota community. Similarly, a more strategic awareness regime should be deployed towards adolescent populations.

\section{Acknowledgement}

We sincerely appreciate all the students (including their parent/ guardian) that participated in this study. We equally thank the management and all the Teacher of Comprehensive Primary School Ikota for their support.

\section{Conflict of interest}

Authors declare that they have no competing interests.

\section{References}

Adewunmi, C. O.; Furu, P.; Chistensen, N. O.; Olorumola, F. Endemicity seasonality and locality of transmission human schistosomiasis in three communities in South-Western Nigeria. Tropical Medical Parasitology, v. 42, no. 4, p. 332-334, 1991.

Akogun, O. B.; Obadiah, S. History of haematuria among school-aged children for rapid community diagnosis of urinary schistosomiasis. Nigerian Journal of Parasitology, v. 17, p. 11-15, 1996.

Anorue, C. O.; Nwoke, B. E. B.; Ukaga, C. N. The incidence of urinary schistosomiasis in
Ohaukwu Local Government Area of Ebonyi. Asian Journal of Biomedical and Pharmaceutical Sciences, v. 7, no. 61, 2017.

Awosolu, O. B. Epidemiology of urinary schistosomiasis and knowledge of health personnel in rural communities of SouthWestern Nigeria. Journal of Parasitology and Vector Biology, v. 8, no. 10, p. 99-106, 2016.

Bala, A. Y.; Ladan, M. U.; Mainasara, M. Prevalence and intensity of urinary schistosomiasis in Abarma Village, Gusau, Nigeria: A preliminary investigation. Science World Journal, v. 7, no. 2, 2012.

Bigwan, B.; Tinja, J. G. Prevalence of schistosomiasis in Potiskum Local Government, Yobe State. Journal of Applied Science, v. 5, p. 1-5, 2012.

Bishop, H. G.; Akoh, R. I. Risk factors, symptoms and effects of urinary schistosomiasis on anthropometric indices of school children in Zaria, Kaduna State, Nigeria. Open Access Journal of Science, v. 2 , no. 1, p. 61-65, 2018. https://doi.org/ 10.15406/oajs.2018.02.00045

Dawaki, S.; Al-Mekhlafi, H. M.; Ithoi, I.; Ibrahim, J.; Abdulsalam, A. M.; Ahmed, A.; Sady, H.; Nasr, N. A.; Atroosh, W. M. The menace of schistosomiasis in Nigeria: Knowledge, attitude, and practices regarding schistosomiasis among rural communities in Kano State. PLoS ONE, v. 10, no. 11, e0143667, 2015. https://doi.org/10.1371/ journal.pone.0143667

Dawet, A.; Benjamin, C. B.; Yakubu, D. P. Prevalence and intensity of Schistosoma haematobium among residents of Gwong and Kabong in Jos North Local Government Area, Plateau State, Nigeria. International Journal of Biological and Chemical Sciences, v. 6, no. 4, p. 1557-1565, 2012. https://doi.org/ 10.4314/ijbcs.v6i4.15

Duna, C.S.; Bristone, A. Urinary schistosomiasis among primary school pupils in Belwa Local Government of Adamawa State. Nigerian Journal of Parasitology, v. 21 , no. 3,2000 .

Hotez, P. J.; Kamath, A. Neglected tropical diseases in sub-Saharan Africa: Review of their prevalence, distribution, and disease burden. PLoS Neglected Tropical Diseases, v. 3, no. 8, e412, 2009. https://doi.org/ 10.1371/journal.pntd.0000412 
Houmsou, R. S.; Amuta, E. U.; Sar, T. T. Profile of an epidemiological study of urinary schistosomiasis in two Local Government Areas of Benue State, Nigeria. International Journal of Medical and Biomedical Research, v. 1, no. 1, p. 39-48, 2012.

Ivoke, N.; Ivoke, O. N.; Nwani, C. D.; Ekeh, F. N.; Asogwa, C. N.; Atama, C. I. Prevalence and transmission dynamics of Schistosoma haematobium infection in a rural community of Southwestern Ebonyi State. Nigeria Journal of Tropical Biomedical, v. 31, p. 77-88, 2014.

Nkengazong, L.; Njiokou, F.; Asonganyi, T. Two years impact of praziquantel treatment on urinary schistosomiasis in the Barombi Kotto focus, Cameroon. International Journal of Biosciences, v. 3, no. 3, p. 98-197, 2013.

Oniya, M. 0.; Jeje, 0. Urinary schistosomiasi: Efficacy of praziquantel and association of the ABO blood grouping in disease epidemiology. International Journal for Biotechnology and Molecular Biology Research, v. 1, no. 3, p. 31-35, 2010.

Reuben, R. C.; Tanimu, H.; Musa, J. A. Epidemiology of urinary schistosomiasis among secondary school students in Lafia, Nasarawa State, Nigeria. Journal of Biology, Agriculture and Healthcare, v. 3, no. 2, p. $73-83,2013$.
Ugbomoiko, U. S. The prevalence, incidence and distribution of human urinary schistosomiasis in Edo State, Nigeria. Nigerian Journal of Parasitology, v. 21, p. 3-14, 2000.

Ugbomoiko, U. S.; Ofoezie, I. E.; Okoye, I. C.; Heukelbach, I. Factors associated with urinary schistosomiasis in two peri-urban communities in South-Western Nigeria. Annals of Tropical Medicine \& Parasitology, v. 104, no. 3, p. 409-419, 2010. https://doi.org/10.1179/136485910X12743 554760469

Umar, A. S.; Parakoyi, D. B. The prevalence and intensity of urinary schistosomiasis among school children living along the Bakalori Dam. The Nigerian Postgraduate Medical Journal, v. 12, no. 3, p. 168-172, 2005.

WHO - World Health Organization. Helminth control in school-age children: A guide for managers of control programmes. Geneva: WHO, 2002. 